\title{
Integrating Natural Resource Damage Assessment and Environmental Restoration Activities at DOE Facilities
}

October 1993

\author{
Prepared for the \\ U.S. Department of Energy \\ Office of Environmental Guidance \\ Washington, D.C.
}

Prepared by

Martin Marietta Energy Systems, Inc.

under contract No. DE-AC05-90OR21851

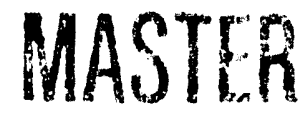

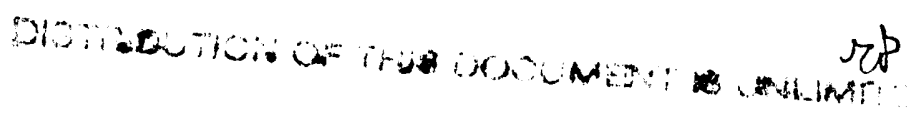




\section{Preface}

This document was prepared by the Office of Environmental Guidance, RCRA/CERCLA Division (EH-231) with the support of the Environmental Compliance Group, Environmental Sciences Division, Oak Ridge National Laboratory and the Natural Resource Damage Assessment Program, Research Triangle Institute. This printing is the original complete version of an exerpted version which appeared in Federal Facilities Environmental Journal, Vol. 4, No. 3, pp. 295-317, Autumn 1993. Questions regarding the subject matter in this document should be directed to Mr. John Bascietto, U.S. Department of Energy, 1000 Independence Avenue, S.W., Washington, D.C. 20585, at (202) 586-7917. 


\section{Integrating Natural Resource Damage Assessment and Environmental Restoration Activities at DOE Facilities}

\section{Introduction}

Environmental restoration activities are currently under way at many U.S. Department of Energy (DOE) sites under the Comprehensive Environmental Response, Compensation, and Liability Act (CERCLA), as amended. DOE is the CERCLA lead response agency for these activities. Section 120 of CERCLA also could subject DOE to liability for natural resource damages resulting from hazardous substance releases at its sites. A Natural Resource Damage Assessment (NRDA) process is used to determine whether natural resources have been injured and to calculate compensatory monetary damages to be used to restore the natural resources. In addition to restoration costs, damages may include costs of conducting the damage assessment and compensation for interim losses of natural resource services that occur before resource restoration is complete. Natural resource damages represent a potentially significant source of additional monetary claims under CERCLA, but are not well known or understood by many DOE staff and contractors involved in environmental restoration activities. This report describes the requirements and procedures of NRDA in order to make DOE managers aware of what the process is designed to do. It also explains how to integrate the NRDA and CERCLA Remedial Investigation/Feasibility Study processes, showing how the technical and cost analysis concepts of NRDA can be borrowed at strategic points in the CERCLA process to improve decisionmaking and more quickly restore natural resource services at the lowest total cost to the public. 


\section{Mandates for Natural Resource Damage Assessment}

\section{Statutory Background}

The "public trust doctrine" is an ancient principle of law that can be traced back to Roman times (1). It provides, in general, that governments hold certain property and natural resources in trust for the benefit of the public and, furthermore, have the duty and authority to protect and preserve such property and resources for public uses. In American law, this doctrine has become highly developed through court cases and through legislation that expressly assigns authority to government "trustees" to protect and preserve public trust properties. Three contemporary environmental statutes, the Clean Water Act (CWA), CERCLA, and the new Oil Pollution Act (OPA), all impose liability for damages resulting from releases of oil or hazardous substances that cause injury to natural resources.

Given that all three of these statutes contain similar natural resource damage liability provisions, a few words of explanation on their respective jurisdictions are needed. The Federal Water Pollution Control Act, otherwise known as the CWA, was the earliest of the three statutes to impose such liabilities. Section 311(f) of the CWA made illegal discharges of oil or hazardous substances into the navigable waters of the United States subject to liability to the United States government for actual costs incurred in their removal.

In December 1980, the Congress enacted CERCLA to clean up sites contaminated by hazardous substance releases and to assure that the public is compensated for natural resource injuries caused by such releases. CERCLA's provisions are not applicable to oil spills. Thus, after the enactment of CERCLA, but before the enactment of the OPA, the CWA continued to provide authority for claiming natural resource damages for oil spills, while CERCLA superseded it for natural resource liabili- 
ties stemming from hazardous substance releases. Implementation of both statutes has been through the shared National Oil and Hazardous Substances Pollution Contingency Plan (2), or NCP, which specifies the organizational structures and procedures for responding to both oil and hazardous substance releases. The Department of the Interior's (DOI's) regulations for conducting the NRDA process (3) are also common to both statutes.

With OPA in 1990, Congress created a new framework applicable to discharges of oil into navigable waters. The OPA applies to all such discharges occurring after August 18, 1990, its date of enactment. OPA's liability provisions now supersede those of the CWA except for cases related to oil spills that occurred before August 18, 1990. Regulations implementing the NRDA process under OPA, to be promulgated by the National Oceanic and Atmospheric Administration (NOAA), have not yet been proposed. This report will, therefore, focus exclusively on the CERCLA/CWA framework.

\section{Statutory Requirements}

CERCLA 107(a) makes current and past owners and operators of vessels and facilities that generated, transported, treated, or disposed of hazardous substances liable for the costs of any removal and/or remediation necessary when a hazardous substance relcase causes response costs to be incurred. CERCLA $107(a)(4)(C)$ specifically enumerates "damages for injury to, destruction of, or loss of natural resources, including the reasonable costs of assessing such injury, de struction, or loss..." among the costs for which responsible parties are liable.

\section{Definition of Natural Resources}

CERCLA 101(16) defines natural resources to mean "land, fish, wildlife, biota, air, water, ground water, drinking water supplies, and other such resources belonging to, managed by, 
held in trust by, appertaining to, or otherwise controlled by the United States..., any State, local government, or any foreign government, any Indian tribe...." This definition has two important aspects. First, it is quite broad, encompassing most of what anyone would readily imagine to be a natural resource. Second, it contains an important limitation, which is that the natural resources to which CERCLA is applicable must be public resources. Although the definition clearly does not limit recovery of natural resource damages to only those resources that are owned by a government, the words "managed by, held in trust by, appertaining to, or otherwise controlled by" indicate that some substantial form of government regulation, management, or control over property is necessary to make it a CERCLA natural resource. In addition, CERCLA does not create a private right of recovery for natural resource or other damages. Rather, CERCLA 107(f)(1) explicitly defines liability as being to the United States, any state, or Indian tribe.

Private individuals cannot recover damages for personal injury, property damage, or economic loss related to natural resource injuries under CERCLA's natural resource damage provisions. Only natural resource trustees may do so. CERCLA's citizen-suit provision in Section 310(a) does, however, allow private parties to sue to enforce any CERCLA requirement or to compel Federal officials to perform non-discretionary duties under the law. This provision can be and has been used to force natural resource trustees to fulfill their NRDA obligations.

\section{Designation of Trustees}

CERCLA 107(f)(1) states that "The President ...shall act on behalf of the public as trustee of such natural resources to recover for such damages." CERCLA $107(f)(2)(A)$ also requires that the President designate in the NCP which Federal officials will act for him as public trustees for natural resources, and CERCLA $102(f)(2)(B)$ requires the governor of each state 
to designate state officials to act as trustees for state trust resources. For Federal resources, Executive Order 12580 and the NCP (4), therefore, designate the Secretaries of Defense, the Interior, Agriculture, Commerce, and Energy as trustees. These officials have the responsibility to assess damages for injury to, destruction of, or loss of natural resources under their trusteeship.

Note that DOE is a designated trustee for natural resources that are on, over, or under land under its jurisdiction and not specifically the responsibility of some other resource management agency. In addition, Section 120 of CERCLA, as amended, specifies that the departments and agencies of the United States government are subject to, and must comply with, CERCLA in the same manner and to the same extent as any nongovernmental entity, including Section 107 liability. Federal facilities that have released hazardous substanccs should, therefore, clearly be concerned about natural resource damage liabilities. In other words, DOE may have a dual role; where DOE activities have resulted in hazardous substance releases, DOE is the CERCLA Lead Response Agency, and as such may be subject to natural resource liabilities to other trustees; but DOE is also the trustee for the natural resources under its own jurisdiction.

Because trusteeship is not solely a function of geographical location, nor is it strictly tied to land ownership, DOE is not likely to be the only trustee for natural resources associated with its sites. Trusteeship also derives from legally established resource management responsibility (5). Therefore, where hazardous substance releases have affected, or may affect, resources managed by other trustees or in which other trustees have interests, DOE may only be in the position of sharing responsibility as a co-trustee. Where there are multiple trustees, a lead trustee may be designated, although there are few specific requirements on when and how such a designation is to be made. Where contaminants have moved outside the boundaries of 
DOE property to affect natural resources offsite, DOE may have no trustee authority at all.

Although the Secretaries named above are the designated Federal trustees, the management of the actual natural resources is typically the responsibility of subagencies of these cabinet Departments. For example, the U.S. Fish and Wildlife Service, under the Department of the Interior (DOI), has management responsibility for migratory birds, threatened and endangered species, and national wildlife refuges. The National Park Service, also part of DOI, has jurisdiction over national parks, national seashores, national recreation areas, and wild and scenic rivers. The National Oceanic and Atmospheric Administration (NOAA), in the Department of Commerce, is also a key agency, with responsibility for coastal environments and habitats, tidal wetlands, marine mammals and sanctuaries, commercial and recreational marine fisheries, and the habitats of anadromous and catadromous fish. The U.S. Forest Service, an agency of the Department of Agriculture, is the manager for national forest resources. It should be noted that the Environmental Protection Agency (EPA) is not a designated Federal trustee. EPA is not a resource management agency, and has no trust resources of its own. EPA is, however, required to notify the natural resource trustees of potential damages from releases that are being investigated at non-Federal facilities, and is expected to coordinate its investigations with those of the trustees.

State trustees, who are named by the governors, are typically the directors of state executive departments that have related responsibilities, e.g., health, environmental protection, natural resources, parks and recreation, etc. Some governors name more than one state trustee. For Indian tribes, the tribal trustee is usually the tribal chairman or the chairman's designee (6). 


\section{Exclusions from Liability}

There are a number of conditions under which CERCLA provides that no natural resource damage liability exists. First, CERCLA 107(f)(1) specifies that no liability shall be imposed where it can be demonstrated that "the damages to natural resources complained of were specifically identified as an irreversible and irretrievable commitment of natural resources in an environmental impact statement, or other comparable environmental analysis, and the decision to grant a permit or license authorizes such commitment of natural resources, and the facility or project was otherwise operating within the terms of its permit or license...." In other words, where specific resource tradeoffs are identified and considered in making the decision to issue a permit or license, no liability for the permitted or licensed releases exists. Ward and Duffield (1), citing the court case Idaho v. Hanna Mining Co., state that "The words irreversible and irretrievable need not be specifically used in the environmental impact statement for the defense to apply, but there should be a clear and unambiguous statement of such a commitment of the natural resources. The defense only applies to natural resource damages from a newly permitted project; it will not relieve a responsible party of liability for damage arising out of past activities." In gerieral, it is not known how the "irreversible and irretrievable" exclusion will apply to Federal facilities.

There are a variety of other questions that arise about the specific applicability of this exclusion. What kinds of documents constitute a "comparable environmental analysis?" Ward and Duffield state that the legislative history of CERCLA indicates that Congress intended such documents to have been prepared by Federal agencies. Are state-prepared environmental analyses, therefore, ineligible? And, if DOE or some other Federal agency is compelled by EPA to perform a CERCLA remedy that itself injures a natural resource (e.g., dredging a 
wetland to remove contaminated soils), can this type of impact qualify for the exclusion if it is identified in an integrated RI/FS-EIS? The answers to such questions remained to be worked out.

CERCLA 107(f)(1) contains another exclusion for situations in which "damages and the release of a hazardous substance from which such damages resulted have occurred wholly before the enactment" of CERCLA, the date of which was December 11,1980 . Courts have interpreted this to apply only when both the release and its resulting damages wholly predated the date of enactment, i.e., all releases ended before December 11, 1980 and no damages were suffered on or after that date (1). Releases that began before the enactment date and continued thereafter would not be eligible for the exclusion, nor would releases that ended before the date that were related to damages occurring past it. One court has ruled, however, that where pre-and postCERCLA damages can be distinguished, only post-CERCLA damages are recoverable. The responsible party, however, bears the burden of identifying the pre-CERCLA damages to be eligible for the exclusion.

Two additional exciusions that are related to other laws are found in CERCLA 107(i) and (j). Section 107(i) prohibits recovery for response costs or damages resulting from the application of a pesticide registered under the Federal Insecticide, Fungicide, and Rodenticide Act. Similarly, Section 107(j) specifies that "Federally permitted releases," or releases that conform to the terms of permits issued under the CWA, Clean Air Act (CAA), Resource Conservation and Recovery Act (RCRA), Atomic Energy Act, and other laws, are ineligible for recovery under CERCLA provided that these releases are in compliance with permit or other licensing terms. Injuries that occur due to releases that are not expressly permitted (e.g., releases from a system malfunction), that exceed permit limitations, or that occur when a permit is not in force are not excluded. 
Understanding the nature and applicability of these various exclusions may be important in determining whether a particular release fulfills the criteria for performing an NRDA according to the process specified by regulation.

\section{NRDA Regulations and Process}

CERCLA 301(c) requires the President to promulgate regulations for the assessment of natural resource damages under both CERCLA and the CWA, and calls for two different sets of regulations, the applicability of which differ situationally. "Type A" regulations are to specify standard procedures for simplified assessments requiring minimal field observation. The statute allows for such situations to be handled by establishing measures of damages based simply on units of discharge/release or on units of affected area. These Type A regulations are used to assess damages only for oil spills in marine and coastal environments. The Type B regulations are to provide alternative protocols for conducting assessments in more complex site specific cases. The Type B process is for damage assessments in all other settings.

Although most of the President's authorities under CERCLA are delegated to EPA, DOI was assigned the task of writing the NRDA regulations. DOI's regulations for both Type A and Type B NRDAs are found at 43 CFR 11. They contain detailed methods for establishing that an injury to a natural resource has occurred, relating the injury to the release of a hazardous substance, quantifying the reduction in resource "services" due to the injury, and computing dollar values for damages. The prescribed procedures can be used by trustees to "determine compensation for injuries to natural resources that have not been nor are expected to be addressed by response actions conducted pursuant to the NCP" (7). Such "residual injuries" are what remains after a Superfund cleanup is complete. 
It is important to note that the OPA also imposes a requirement for the promulgation of regulations for conducting NRDAs specifically for oil spills. In this case, however, it is NOAA that has been delegated this authority. Once the new NOAA regulations are promulgated, they will supersede the DOI regulations discussed here for oil spills, while the DOI regulations will continue to apply for hazardous substance releases. Until then, however, the DOI regulations will remain in force for both hazardous substance releases and discharges of oil.

Before describing the procedures specified in the DOI rule in detail, several points need to be made. First, definitions for a variety of terms used in the NRDA framework are important, and some may differ from common everyday usage. All are found in 43 CFR 11.14. Injury, in the NRDA context, generally means "a measurable adverse change, either long- or short-term, in the chemical or physical quality or the viability of a natural resource...." Thus, the term injury refers to the actual harm that occurs to the natural resource. As defined by DOI, injury also encompasses the terms "destruction" and "loss." More detailed injury definitions applicable to specific categories of resource are given in 43 CFR 11.62. Damages means the amount of money sought by the Federal and/or state trustees as compensation for injury. Thus, these two terms mean very different things, and cannot be used interchangeably as they may be in everyday speech. Services means the physical and biological functions performed by a natural resource, including human uses of those functions. These services are the result of the physical, chemical, or biological quality of the resource. An injury that reduces resource quality, therefore, may also reduce the services the resource provides. Restoration and/or rehabilitation refer to actions undertaken to return an injured resource to its baseline, or without-release, condition as measured in terms of the injured resource's physical, chemical, or biological properties or the 
services it would have provided. Note that this definition of restoration is not necessarily the same as DOE's use of the term "environmental restoration," which emphasizes cleaning up past releases and existing contamination. Replacement or acquisition of the equivalent mean the substitution of another resource that provides the same or substantially similar services for a resource that was injured. It should be noted that damages collected as compensation for resource injury by the trustees can only be used for the restoration, rehabilitation, replacement, or acquisition of the equivalent of the injured resource.

Second, use of the assessment procedures in 43 CFR 11 is not iriandatory. But because use of the DOI procedures conveys a "rebuttable presumption" to the of ficials acting as trustees under CERCLA 10 ? $(\mathrm{f})(2)(\mathrm{C})$, following the prescribed process has advantages. In the event of a dispute between the responsible party and the trustees over the validity of estimated damages, the responsible party would have the burden of proving the damage estimate invalid if the trustee used the procedures in the DOI rule and obtained the rebuttable presumption. The rebuttable presumption is, however, primarily of importance in the event of litigation. Few natural resource damages cases have, in fact, actually been tried (6), with most being settled out of court. The primary reason to acquaint DOE facility managers with the DOI procedures is not necessarily to prepare them to conduct the NRDA process. Rather, it is to make them aware of what the process is designed to do and how its technical and cost analysis concepts can be borrowed at strategic points in the CERCLA process to improve environmental restoration decisionmaking and minimize potential natural resource damages liabilities in the future.

The next sections, therefore, describe the four phases of the NRDA process as provided in the DOI rule, incorporating proposed changes as a result of a 1989 court decision. [In Ohio $v$. Interior (8), various provisions of the DOI regulations were 
challenged. The U.S. Court of Appeals, D.C. Circuit, issued its ruling in July of 1989 , remanding some provisions to DOI for revision]. We encourage the reader to consult 43 CFR Part 11 and two Federal Register notices (9) concerned with DOI's proposed revisions to 43 CFR 11 for full details.

\section{Preassessment Screen}

The purpose of the Preassessment Screen is to determine whether a release justifies performing an NRDA. Conducting an assessment can be a costly and time consuming endeavor, and trustees are expected to do so only when circumstances justify it. The Preassessment Screen is based on a review of readily available data, and is used to make a "go/no go" decision. The trustees must determine the answer to each of the following questions:

1. Has a release of a hazardous substance occurred?

2. Have natural resources been adversely affected by the hazardous substance release?

3 . Is the quantity and concentration of the released hazardous substance sufficient to potentially cause injury to those natural resources?

4. Are data sufficient to pursue an assessment readily available or obtainable at reasonable cost?

5. Will response actions not be sufficient to remedy the injury without further action?

The answer to all five questions must be "Yes" in order for trustees to proceed with a damage assessment.

Performing the following steps generally provides enough information for the trustees to answer the five questions: preliminary identification of substance released and its source; 
determination that release the is covered under CERCLA or CWA, and not subject to any of the statutory exclusions; initial estimates of the exposure pathway; identification of exposed areas; estimates of exposure concentrations; identification of potentially injured resources; and preliminary determination of potential benefits of performing an NRDA relative to the potential costs.

\section{Assessment Plan}

When the Preassessment Screen indicates that a damage assessment is appropriate, the trustees then prepare an Assessment Plan. The Assessment Plan involves planning, coordination, and involvement of the public, potentially responsible parties (PRPs), and trustees. The Assessment Plan should ensure that the assessment is performed in a systematic manner and at a reasonable cost.

The three main steps in the Assessment Plan are:

- Confirmation that at least one of the identified natural resources has been injured by the release.

- Decision to proceed with a Type A or Type B assessment. Since Type A assessments are not applicable to DOE sites, we hereafter focus strictly on the Type B assessment.

- If a Type B assessment is appropriate, the Trustee then completes the final step of preparing the Assessment Plan itself. This plan must be available for public comment.

The Assessment Plan should identify and document the methodologies that will be used in the Type B assessment. Proposed revisions to the regulations also require that a preliminary estimate of damages and a Restoration and Compensation Determination (RCD) Plan be developed during the Assessment Plan phase. The preliminary damage estimate is intended to be a back-of-the-envelope calculation using existing information. 
Its goal is to ensure that assessment costs are "reasonable," that is, less than the damages calculated in the assessment. The preliminary estimate should be used to determine the appropriate scale of the assessment; it should include both preliminary estimates of restoration costs and the values that are lost prior to restoration.

The RCD Plan should provide information on: possible restoration alternatives, natural resource service losses associated with each restoration alternative, the selected alternative, the selection rationale, and the methodologies for determining the cost of the selected alternative and the "compensable value" (see Damage Determination, below) of foregone natural resource services associated with this alternative. If the available data are insufficient, both the preliminary damage estimate and the RCD Plan can be postponed until later stages of the assessment.

\section{Type B Assessment}

In this phase, the actual damage assessment is performed. It consists of three steps: Injury Determination, Quantification of Service Effects, and Damage Determination.

\section{Injury Determination}

The purpose of the Injury Determination step of the NRDA is to establish that injury of a resource has occurred as the result of a hazardous substance release. This involves determining that an injury meeting specific definitions has occurred and documenting that there exists a pathway by which the release could have caused the observed injury.

\section{Injury Definitions}

The DOI rule (43 CFR 11.62) divides natural resources into five categories-surface water, ground water, air, geologic resources, and biological resources. Specific injury definitions are then given for each category. 
For surface water resources, there are three kinds of changes defined as injury. These are the presence of contaminants in potable drinking water in excess of the standards or criteria of the Safe Drinking Water Act (SDWA); the presence of contaminants in excess of the standards or criteria of the CWA; or the presence of contaminants in sufficient concentration to cause bed, bank, or shoreline sediments to exhibit the characteristics of a hazardous waste as defined under RCRA. In addition, there is a fourth "catch-all" change, which is the presence of contaminants in concentrations sufficient to injure other resources when exposed to the water. For example, if a water body contained a contaminant that injured its resident fish, this would also constitute an injury to the surface water. For the above definitions of injury to be met, appropriate oil or hazardous substance concentrations must be detected in two water or sediment samples separated by specified distances or time.

Similarly, injuries to ground water resources involve the presence of contaminants in excess of SDWA or CWA standards or criteria, or in concen rations sufficient to injure other resources. Again, two water samples collected in the appropriate manner and places must exhibit the contamination.

Injuries to air resources involve emissions of hazardous air pollutants in excess of the CAA or other Federal or state standards for the protection of public welfare. Again, the catchall of emissions sufficient to have caused other injury is also provided in the DOI definition.

For geologic resources, injury is defined by a longer list of physical or chemical changes. These are contaminant concentrations sufficient to cause materials to exhibit the characteristics of a hazardous waste under RCRA; lower or raise soil $\mathrm{pH}$ to below 4.0 or above 8.5 ; yield a sodium absorption ratio above 0.176 ; decrease water holding capacity; impede microbial respiration; inhibit carbon mineralization; restrict ability to 
access, develop, or use mineral resources; injure ground water (see above); cause a toxic response to soil invertebrates; cause a toxic response to plants, such as retardation of plant growth; or cause injury to other resources, as above.

Injuries to biological resources are the most complex. There are three criteria. First, an injury has been caused if a biological resource has undergone an adverse change in viability, which may consist of death, disease, behavioral abnormalities, cancer, genetic mutations, physiological (including reproductive) malfunctions, or physical deformation. Second, an injury has occurred if the edible portions of an organism exhibit contaminant concentrations in excess of Food, Drug, and Cosmetic Act action or tolerance levels. Similarly, the third criterion is defined as the presence of contaminants exceeding levels established by a state health agency to limit or ban (human) consumption.

Establishing that biological injuries have occurred requires the use of methods that demonstrate measurable biological responses. All of the following acceptance criteria must be satisfied: the biological response is often the result of exposure to oil or hazardous substances, and must be a commonly documented response to such an exposure; such an -xposure is known to cause the same biological response in free-ranging organisms; such an exposure is known to cause the same biological response in controlled experiments,; and the measurement of the biological response is practical to perform and produces scientifically valid results. Injury determinations must also be based on the establishment of statistically significant differences in biological responses between populations in assessment and control areas.

The DOI has itself evaluated certain kinds of biological responses and determined that these satisfy the above acceptance criteria. They are listed in 43 CFR 11.62, and include observations of such phenomena as inhibited brain choli- 
nesterase activity, fin erosion, fish neoplasm, eggshell thinning, and reduced avian or fish reproduction. The reader is encouraged to consult the DOI regulations for the many complex details of these test methodologies. Other tests not specifically listed in 43 CFR 11.62 may also be used to demonstrate biological resource injury so long as the four acceptance criteria given above are met.

\section{Pathway Determination}

Injury determination also requires the linking of injuries established using the above criteria to a release of a hazardous substance by determining the pathway of exposure. This pathway may be demonstrated directly by the presence of the hazardous substance in concentrations sufficient to meet injury definitions in the pathway itself; or by using a modeling approach to demonstrate that conditions along the suspected pathway and the nature of the hazardous substance released make it a plausible route of exposure. Consideration must be given to the physical and chemical characteristics of the released substance, the rate or mechanism of transport by natural processes, and to combinations of possible pathways.

For each type of pathway (i.e., surface water, ground water, air, geologic, or biological), trustees are expected to use available information and/or additional tests to evaluate such factors as mobility of the hazardous substance (related to its solubility, density, volatility, potential for degradation or precipitation, biological uptake, and adsorption), rate of transport (time-oftravel and dispersion in various media), and potential for indirect exposure via phenomena such as food chain processes. The reader should consult 43 CFR 11.63 for further information on pathway determination.

In addition, 43 CFR 11.64 provides detailed guidance on the selection and use of testing and sampling methods. Testing and sampling methods must be appropriate for the conditions of the 
assessment area, be cost effective, produce diata that were previously not available, and provide data that are appropriate for the needs of the next phase of the NRDA, the Quantification of Service Effects.

\section{Quantification of Service Effects}

The purpose of the second step in a damage assessment is to quantify the reduction in natural resource services resulting from the injuries attributable to a hazardous substance release. Natural resource services are defined in the NRDA regulations as the functions one resource performs for another resource or for humans. It is important to note that a service is distinct from a physical or biological condition in that a service describes the interaction between species, species and humans, or between physical and bio ' gical elements. Examples of important services are the support of fishing activities by a bay or estuary, or the provision of habitat for endangered species, such as the brown pelican.

In this step the natural scientists documenting resource injuries work with economists to measure the effects of the injuries on natural resource services. Although this interdisciplinary interaction is essential, this step in the NRDA process does not generally receive the attention it deserves. Many of the NRDAs performed to date have focused almost exclusively on determining injury or measuring damages without making the necessary connections between the two. It is the reduction-in-services step that determines the quantity benchmarks for the damage assessment (e.g., "What is the baseline level of recreation days and how did they change in response to the release?") Moreover, the service information is essential for the evaluation of restoration alternatives, because restoration is aimed at restoring the affected services of the injured resources. Finally, the service information is essential for measuring the economic losses associated with reduced services in the damage calculations, which we describe below. 
In general, natural resource services can be divided into two types: use services and nonuse services. Use services involve some physical or visual contact between people and the natural resources. Examples of use services include boating, fishing, hunting, and bird watching. In general, the most common source of natural resource damages is the reduction or elimination of recreational uses ("foregone recreational activities") by a hazardous substance release.

Nonuse services do not require physical or visual contact between people and natural resources. Nonuse services can arise because natural resources provide well-being to people merely because they exist. That is, natural resources may be deemed to have nonuse value in spite of the fact that someone may never or in any way come in contact with the resource. Examples of natural resources that may provide nonuse services include unique geologic resources, such as the Grand Canyon, and rare, threatened, or endangered species, such as bald eagles.

In the proposed revisions to the NRDA regulations, use services are defined as associated with "direct" uses of natural resources, while nonuse services are identified as all other natural resource services, presumably including "existence services" and the services that resources provide for other resources. The latter are mainly limited to the provision of food, nest sites, protection from predators, and similar biotic support services. Normally, these services directly or indirectly influence use and/or nonuse services. Thus, the impact of services provided to other natural resources is incorporated into measures of use and nonuse services to the extent possible in order to avoid double-counting some services.

Baseline services refers to pre-release services and expected post-release services assuming that the release did not occur (Figure 1). Post-release baseline service estimates should reflect conditions that would have been expected at the assessment area 
had the release not occurred, taking into account both natural variations in natural resources (e.g., seasonal variations in fish abundance) and those variations that are the result of non-release human activities (e.g., the impact of agricultural runoff on

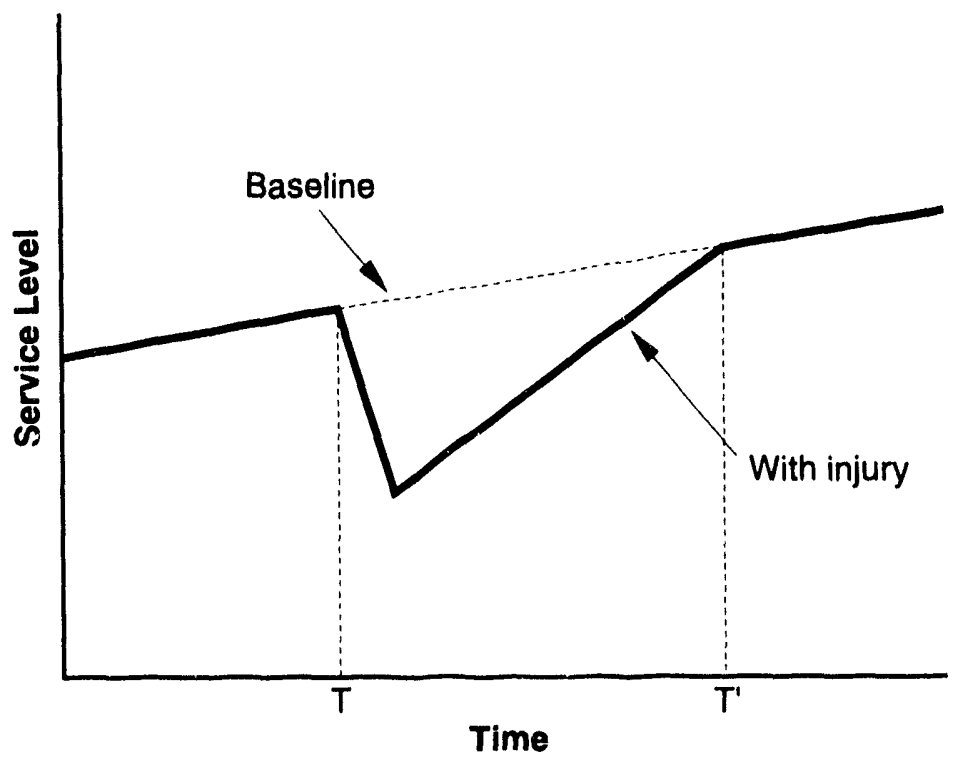

Figure 1. Baseline and with-injury service levels for a release occurring at time $T$, with natural recovery by time $T^{\prime}$

fish s'oundance). Service reductions attributable to a release are based simply on the difference in with-injury service levels and baseline service levels (Figure 1). It is not appropriate to measure service reductions as the difference in service levels before and after a release. Before-and-after comparisons ignore potentially important influences on service levels that are completely 
unrelated to the release. For example, suppose a drought adversely affects fish abundance, and fishing services, in a release area in the months immediately following a release. A beforeand-after comparison would attribute all of the reduced fishing services to the release, while a with-and-without comparison would focus solely on the effect of the release on fishing services, over and above the effect of the drought on fishing services.

The determination of baseline service levels should rely as much as possible on historical data and known relationships between service levels and non-release factors. The NRDA regulations list specific sources that may have useful historical data. When historical data on natural resource services are unavailable or inadequate, the NRDA regulations allow the use of data from nearby reference areas to estimate baseline service levels in the release area. Reference areas should be selected based on their similarity to the release area and lack of exposure to the released hazardous substance. The reliability of data from reference areas depends on the extent to which services in the reference area accurately reflect services that the injured natural resources would have provided without the injury.

The precision of baseline service estimates depends on several factors. As indicated above, historical data on the release area are preferred for estimating baseline service levels, because these data most accurately reflect the physical, chemical, and biological conditions in the area. However, estimating post-release baseline services requires the extrapolation of historical data. Consequently, the precision of baseline service estimates decreases as the length of the injury-period increases, because there is an increase in the likelihood of omitting changes in resource services that would have occurred without the injury. Alternatively, the reliability of data from reference areas depends on the extent to which the services in the reference area accurately reflect the services that the injured natural resources 
would have provided without the injury. The greater the similarity of the reference area to the release area, the greater the accuracy of the baseline services estimates.

The next step in determining natural resource service reductions from a hazardous substance release is to measure post-release service levels from the time of the release until baseline service levels are restored in the absence of any restoration efforts beyond response actions. (See the with-injury service line in Figure 1). If the damage assessment is conducted before the with-injury service levels have returned to the baseline service levels, then service levels will need to be projected for the time period after the damage assessment until the restoration of baseline service levels. (As explained above, the precision of the projected post-assessment service levels will generally decrease as the length of time between the assessment and the restoration of baseline service levels increases.) The NRDA regulations (43 CFR 11.73) discuss factors that may influence recovery times and list possible sources of information for estimating recovery times.

\section{Damage Determination}

Natural resource damages are the sum of restoration costs (if any), plus the diminution-in-value of foregone natural resource services prior to restoration (or "compensable value" in the proposed revisions to the NRDA regulations), plus damage assessment costs. Compensable value is defined as the amount of money required to compensate the public for natural resource service losses between the time of the release and the time when these services are fully restored to their baseline condition. Compensable value excludes any losses associated with secondary economic impacts resulting from the release, such as losses incurred by businesses patronized by users of the injured resources (e.g., bait and tackle shops). 
Restoration actions should be designed to return post-spill natural resource services to baseline levels sooner than natural recovery would. Thus, restoration actions can decrease the amount of natural resource services foregone as a result of a hazardous substance release. The value of the reduction in natural resource services foregone represents the benefits of the restoration actions. Of course, restoration actions also involve costs. According to Ohio v. Interior, trustees should implement restoration actions unless the costs of these actions are "grossly disproportionate" to their benefits.

The proposed changes in the NRDA regulations provide some guidance on the components of restoration costs, which are defined as the sum of the direct and indirect costs of the selected restoration alternatives. Direct costs are those costs "charged directly to the conduct of the selected alternative including, but not limited to, the compensation of employees for the time and effort devoted to the completion of the selected alternative; cost of materials acquired, consumed, or expended specifically for the purpose of the action; equipment and other capital expenditures; and other items of expense ... that are expected to be incurred in the performance of the selected alternative." Indirect costs are the "costs of activities or items that support the selected alternative, but that cannot practically be directly accounted for as costs of the selected alternative." Overhead (e.g., the administrative costs of processing invoices resulting from the implementation of the selected alternative) is an example of an indirect cost.

The proposed regulations list six possible restoration cost-estimating methodologies: comparison methodology, unit methodology, probability methodologies, factor methodology, standard time data methodology, and cost- and time-estimating relationships. They also allow the use of other cost-estimating methodologies that are based on "standard and accepted cost accounting practices." 
Similar to restoration costs, damage assessment costs include the direct (i.e., labor, materials, equipment, travel, and other out-of-pocket costs) and indirect costs of acquiring and analyzing the information necessary to estimate natural resource damages. This may include studies of the chemical characteristics of the released hazardous substances, pathway and exposure studies, injury determination studies, quantification of the reduction in natural resource services, identification and selection of restoration alternatives, and a determination of use and nonuse damages. All of these studies must be clearly linked to the hazardous substance release.

The diminution-in-value, or compensable value, component of natural resource damages attempts to value the natural resource services that are foregone as a result of a hazardous substance release. The regulations specify that consumer surplus is the basis for valuing foregone services. In the remainder of this section we explain the meaning of consumer surplus and then briefly describe the methods economists use to measure consumer surplus for use and nonuse services.

Economists assume that individual judgments are the appropriate basis for measuring well-being or satisfaction. In economics, "utility" is an abstract measure of individual well-being, and economists assume that people make decisions that will maximize utility. Suppose that a hazardous substance release injures a site, reducing its utility for swimming and picnicking. The economic basis of compensation for the injuries to the site from the hazardous substance release is the amount of money needed to offset the reduction in utility resulting from the injuries.

As a scale for approximating changes in utility, money may not be ideal, but it does have certain desirable properties for obtaining empirical estimates of changes in utility. For example, money imposes certain measurement rules and benchmarks on values. At least within a certain range of preferences, people are 
familiar with the process of expressing their value for something by determining its monetary equivalent. But the expression of value in terms of money is controversial for natural resource services. Some psychologists argue that the values that people have for natural resource services are only vaguely defined. In effect, psychologists question whether people have a well-defined set of preferences for commodities like natural resource services. They also argue that people have a difficult time using money and its cardinal rules of measurement to express their loss in utility from reductions in natural resource services.

Does a lack of well-defined preferences imply that we cannot measure natural resource damages from a hazardous substance release? The answer is that measurement of these damages will likely be more approximate than it would be for commodities regularly bought and sold in markets. Nevertheless, monetary measures of natural resource damages can be expected to exhibit certain common sense characteristics. For example, injuries to rare or endangered birds should be valued more highly than injuries to common birds. While markets may not exist for many natural resource services (such as a day of swimming or picnicking), the methods described below show how it is possible to link natural resource services to a market choice or to simulate a market for natural resource services to elicit values.

Economics has two basic criteria for measuring the value of foregone utility from a reduction in natural resource services:

- Willingness-to-pay criterion-How much would an individual be willing to pay to have avoided the reduction in natural resource services?

- Willingness-to-a:cept criterion-How much compensation would an individual require to be as well off as he or she was before the reduction in natural resource services occurred? 
The willingness-to-pay (WTP) criterion obtains an individual's value for a natural resource service reduction by determining how much he/she would have paid to avoid it. The amount he/she would have paid is the monetary equivalent of the change in utility. The WTP criterion, however, depends on an individual's ability to pay. That is, the individual is limited, by income or wealth, in determining the value of the reduction in utility. Thus, any estimates of value are affected by the distribution of income that exists at any point in time. Of course, income is not the only factor that affects value, simply an important one.

The willingness-to-accept (WTA) criterion asks how much compensation an individual would require to be at the same level of utility or well-being as before the injury. The amount accepted is the monetary equivalent of a change in utility. With this criterion, an individual translates the change in utility into a dollar equivalent without being constrained by his/her existing level of income. Clearly, the role that income plays in valuation distinguishes the two criteria.

Does the WTP criterion give a different estimate of damage than the WTA criterion? For a wide range of goods and services, economists have argued that any differences in empirical estimates of value from the two criteria should be small. This is especially true for goods and services that have small income effects (i.e., ones where differences in an individual's income level would not have much effect). However, some recent research finds large differences between WTP and WTA for natural resource services, with WTA being considerably higher than WTP. Some economists feel that this is consistent with economic theory when there are few substitutes for the natural resource services. Furthermore, psychologists argue that the large difference indicates a dichotomy in people's preferences-they value payments to avoid losses differently than payments compensating them for losses. 
Does one criterion seem more suitable than the other for measuring natural resource damages? Theoretically, the WTA criterion is more germane for assessing natural resource damages, because it focuses directly on the amount of money necessary to compensate people for reductions in natural resource services. However, measuring WTA involves more technical difficulties and uncertainties than measuring WTP. Consequently, the NRDA regulations require the use of the WTP criterion, acknowledging that this measure may understate damages in some cases.

Frequently, economists use concepts that are an empirical compromise for the utility-based valuation measures. One such concept is that of an individual demand function, shown in Figure 2. This function describes for any good or service, such as bread, the maximum quantity of that good that an individual would be willing to purchase at each price per some unit of time. The downward slope of the curve indicates that individuals are willing to buy more bread at lower prices than at higher prices.

The simple diagram in Figure 2 assumes that all other factors that might influence demand, such as income, the prices of related goods, and tastes or preferences, are held constant. The demand function provides a systematic way to measure people's values for goods and services. Figure 2 shows that if the market establishes a price of $\$ 1$ per loaf, people will purchase 1,000 loaves of bread for a total expenditure of $\$ 1,000$. When the price is $\$ 2$ per loaf, however, fewer people are willing to buy bread, and when the price is $\$ 2.50$, no one buys it. Since the area under a demand curve measures the maximum willingness to pay (WTP) for a given amount of a good or service, the total WTP for 1,000 loaves of bread is $\$ 1,750$, the entire area undei the demand curve for the 1,000 loaves of bread. The difference between what people actually pay and the amount they are willing to pay (i.e., $\$ 1750-\$ 1000=\$ 750$ for the 1,000 loaves of bread) is known as "consumer surplus." This is the dollar 
measure of the satisfaction that people receive from consuming the bread, less what they actually pay for it. As a dollar measure of individual welfare, consumer surplus is not ideal, but most studies have found it to be a good empirical approximation of more theoretically desirable measures.

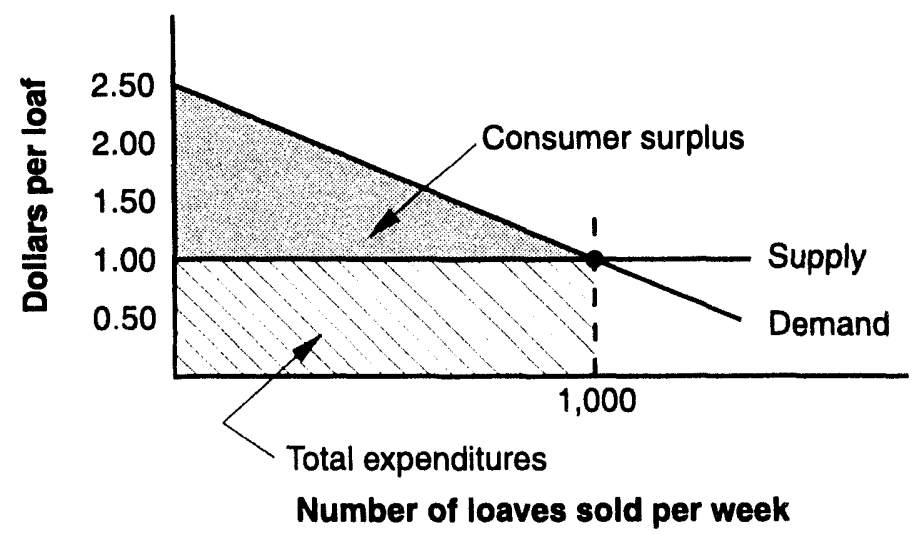

Figure 2. Consumer surplus for loaves of bread

Economists use consumer surplus to value natural resource services in damage assessments based on the WTP criterion. Some non-economists mistakenly use people's expenditures on natural resource services (like sport fishing) as the value of those activities instead of consumer surplus. This is incorrect for several reasons. First, expenditures for the lodging, food, and transportation associated with sport fishing only reflect the value that people place on lodging, food, and transportation, not on fishing itself. There is no reason to think that an angler who stays in an expensive hotel values their fishing experience more highly than an angler who stays in an inexpensive campground 
while fishing. Second, if an angler cannot go fishing, what have they lost? They have not lost the money that they would have spent on lodging, food, and transportation if they had gone fishing. In fact, they still have that money to spend on other goods and services. But they have lost the value of the satisfaction that they would have experienced from spending that money on fishing.

Is consumer surplus for natural resource services less than or more than people's expenditures on these services? The consumer surplus for many natural resource services requiring a lot of equipment (such as boating) tends to be less than expenditures on those services, and consequently, expenditures will overestimate the true value of these services. Alternatively, consumer surplus may be greater than expenditures for natural resource services involving very low cost, such as picnicking and swimming, where expenditures will underestimate the true value of the natural resource services.

There are several possible methods for valuing consumer surplus associated with natural resource use services, but the Travel Cost and Contingent Valuation methods are the most widely used, state-of-the-art methods. The Travel Cost (TC) method has been used to estimate the value of natural resource services in a wide variety of situations, including damage assessments. The TC method is based on the notion that recreationists at a particular site pay an "implicit" price for using natural resource services through their travel and time costs. Since recreationists come from diverse locations, economists can use their "travel behavior" to statistically estimate a demand curve for a site's services. (Data on travel costs are usually obtained from surveys of recreationists at specific sites.) The average consumer surplus associated with this site's services can then be determined from this demand curve. Average consumer surplus times the reduction in natural resource services 
from a hazardous substance release (for example) produces an estimate of the damages to these natural resource services.

Three important issues arise in using the TC method for assessing natural resource damages. First, it is very important to determine the relevant market for the natural resource services. The relevant market includes the geographical area that encompasses the alternative sites that people consider when making their decision to fish (for example) at a particular area. Are there nearby sites that are attractive for fishing? Are these sites easily accessible? Do these sites offer the same types of fishing? The answers to these and other questions will influence the degree of substitutability for the injured natural resource. The greater the number and quality of available substitutes, the smaller will be natural resource damages.

The second issue involves selecting a relevant sample of visitors to the injured site. To have a representative sample of visitors, it is necessary to sample the relevant access points, the types of fishing (e.g., bank or boat), and the various seasons of the year. It is also important to select the sample so that each person has an equal chance of being selected. This prevents people who make multiple visits from having a higher chance of being selected for sampling.

The third and final issue involves the measurement of the implicit price for a visit to the injured site. Because fees are not charged for many recreation areas, it is necessary to calculate an implicit price for the visit. This price includes both the out-of-pocket travel costs (e.g., mileage, food, lodging costs) as well as the opportunity cost of the visitor's time (e.g., the value of the visitor's time spent recreating). While there is currently no consensus in the economics literature on measuring the opportunity cost of time, there are some useful guidelines. It is also important to ensure that the sole purpose of the trip is to engage in recreation at the affected area. (Trips combining 
business and recreation should not be included in the implementation of the TC method.)

Instead of using travel costs to estimate consumer surplus, the Contingent Valuation (CV) method uses surveys to directly elicit individuals' consumer surplus for different levels of natural resource use services. The average consumer surplus, in conjunction with the reduction in natural resource services, is then used to estimate natural resource damages.

The CV method requires that individuals be able and willing to express their value for hypothetical changes in natural resource services in a survey. The sampling and survey procedures are crucial factors when using the $\mathrm{CV}$ method, because these procedures determine who is interviewed and how the questionnaire will be administered. While some critics view CV surveys as merely public opinion surveys that produce unreliable information, many economists have derived values for natural resource use services from carefully designed and implemented $\mathrm{CV}$ surveys that are comparable to values derived from the TC method and other methods for similar services.

The survey questionnaire is the cornerstone of the hypothetical "market" used in the CV method. It generally consists of the following sections:

- Introduction and statement of purpose

- Non-valuation questions (e.g., attitudes and prior knowledge of the injured natural resource services)

- Scenario development and market definition

- Bidding or valuation questions

- Demographics (e.g., age, education, income, marital status). 
The scenario development and market definition section is the most critical, because it must carefully describe the alternative levels of natural resource services. Ultimately, the goal of scenario development is to establish circumstances that represent the way a market would operate for the natural resource services. Verbal or written descriptions, supplemented by visual aids, are often used in this scenario development to make it informative and realistic. Descriptions of natural resource services must be consistent with physical circumstances, credible, and understandable to the survey respondent. Undoubtedly, writing an effective questionnaire is a difficult task. As noted for the TC method, determining the relevant market for the affected natural resource services and selecting samples for the surveys are also very important factors in using the CV method.

While various economic studies have demonstrated that both the TC and CV methods produce estimates of use values that are reasonably accurate, problems can arise in estimating the loss of use values associated with a hazardous substance release. For instance, it can be difficult to establish reliable baseline estimates of natural resource use services when the release has occurred over long periods of time, possibly decades. When there are multiple sources of hazardous substances, it is often difficult to apportion use damages among the sources (or PRPs). Finally, it is sometimes difficult to link the injuries from a hazardous substance release to changes in the use of the injured natural resources.

The CV method is the only one available for estimating the value of nonuse services, and while using the CV method to measure use values is well established, its use in estimating nonuse values is very controversial. The main problem is that, unlike use services, people have no experience in valuing nonuse services. For example, people may feel that preserving endangered species is important, but have trouble translating that feeling into dollars and cents. This is most likely to be the 
case where people are asked to value natural resource services that are unfamiliar to them.

In Ohio v. Interior, the Court ruled that nonuse values that can be reliably measured should be included in compensable value. But some recent nonuse studies have concluded that $\mathrm{CV}$ does not produce reliable estimates of nonuse values. (See, for example, 10). Consequently, as part of developing the new OPA NRDA regulations, NOAA formed a blue-ribbon panel chaired by two Nobel-prize-winning economists to evaluate the reliability of CV-derived nonuse values. Some of the concerns of the NOAA panel about the CV method were that:

1. respondents give answers that are inconsistent with rational choice,

2. willingness to pay responses are implausibly large given the number of possible natural resource services that people might value and existence of substitutes for these services,

3. relatively few previous $\mathrm{CV}$ studies have forcefully reminded respondents of their budget constraints,

4 . it is difficult to provide adequate information to respondents about the natural resource services for which values are being elicited and to be sure they have absorbed and accepted this information as the basis for their WTP response,

5. it is difficult to determine the "extent of the market" for the natural resource services, which is very important for developing aggregate value estimates, and

6. respondents may actually express their "warm glow" for giving, rather than their actual willingness to pay for the natural resource services in question. 
Despite these concerns, the NOAA panel concluded that under certain conditions " $\mathrm{CV}$ studies can produce estimates (of nonuse values) reliable enough to be the starting point of a judicial process of damage assessment" (11). The Panel provided guidance on what it believed to be the conditions necessary for developing reliable CV estimates of nonuse values in an appendix to their final report (12).

While the NOAA panel's conditions for developing reliable $\mathrm{CV}$ estimates of nonuse values are stringent, this conclusion is not universally accepted by economists and others involved in assessing natural resource damages. Furthermore, fulfilling these conditions will be very expensive and time-consuming, and could greatly increase damage assessment costs. The CV survey conducted by the state of Alaska on the nonuse values foregone as a result of the Exxon Valdez oil spill, for example, came close to meeting the NOAA panel's conditions. That survey cost about $\$ 3$ million and took over two years to complete.

\section{Post-Assessment}

The purpose of the Post-assessment phase is to compile a record, recover the natural resource damage award, and develop a detailed plan for restoring/replacing the injured natural resources. The specific activities involved in this phase are:

- Preparing the Assessment Report. The trustees document the results of the major steps in the process, and file the document with a court or other administrative body if seeking a rebuttable presumption.

- Presenting the claim for damages. The trustees present the responsible parties with the results of the assessment and the claim for damages. The responsible parties have 60 days to acknowledge and respond to the trustee's demands. 
- Setting up a restoration account. The recovered damages are placed in a special account within the U.S. Treasury (when awarded to a Federal trustee) or a state treasury or trust fund. These procedures ensure that the funds will be available for restoration without the necessity of going through an appropriations process. Reimbursements for assessment costs are, however, returned directly to the Federal or state treasury that incurred the costs.

- Developing a restoration plan. The trustees then develop a detailed restoration plan, which should describe the management actions that will be taken to restore, rehabilitate, replace or acquire equivalent resources consistent with the damage award. It also describes how the damage award will address the services that are foregone prior to the restoration of baseline conditions.

\section{Integrating the RI/FS and NRDA Processes}

Having described the major steps in the NRDA process, we now shift our focus to integrating the NRDA process with CERCLA RI/FS activities, which should result in the restoration of environmental services sooner and at lower cost to the public. We begin by briefly reviewing the CERCLA process, emphasizing elements that are most similar or relevant to NRDA. We then discuss the linkages between the two processes and provide our recommendations on integrating them, evaluating both the advantages and disadvantages.

\section{The CERCLA Process and Its NRDA Relevant Aspects}

The RI/FS process is EPA's methodology for characterizing the nature and extent of risks to human health and the environment posed by CERCLA sites and for evaluating remedial action alternatives. The objective of the RI/FS is to obtain 
sufficient information to support an informed risk management decision regarding which remedy is most appropriate for a given site. The challenge for a remedial project manager (RPM) is to use the flexibility built into the process to conduct an RI/FS that achieves cost-effective, high-quality results while appropriately managing the uncertainties inherent in remediating uncontrolled hazardous waste sites.

The RI/FS process (Figure 3 ) begins with scoping, a crucial planning phase. Many of the planning steps initiated in this phase are, however, expanded and refined later. Scoping typically commences with the collertion of existing site data, including data from previous investigations. Site management planning is undertaken to make a preliminary identification of the boundaries of the study area, the likely remedial action objectives, and whether interim actions may be necessary and appropriate. Initial data-quality objectives are also identified. RPMs must also decide whether the site will be remediated as a single unit or at "operable units" (OUs), which may be discrete locations, such as plots of contaminated soils or fenced production areas containing contaminated facilities. Actions taken is discrete environmental media can also be OUs, as in a groundwater OU focused on containing or cleaning up a contaminated plume.

Remedial actions under CERCLA (14) must meet the "applicable or relevant and appropriate requirements" (ARARs) of Federal and state laws pertaining to environmental protection. (On-site actions need meet only the substantive, not the administrative, requirements). Preliminary identification of potential ARARs is accomplished during RI/FS scoping. Scoping is usually completed with the preparation of several work plans, such as the sampling and analysis plan (which itself consists of a quality assurance project plan and a field sampling plan), a health and safety plan, and a community relations plan. 


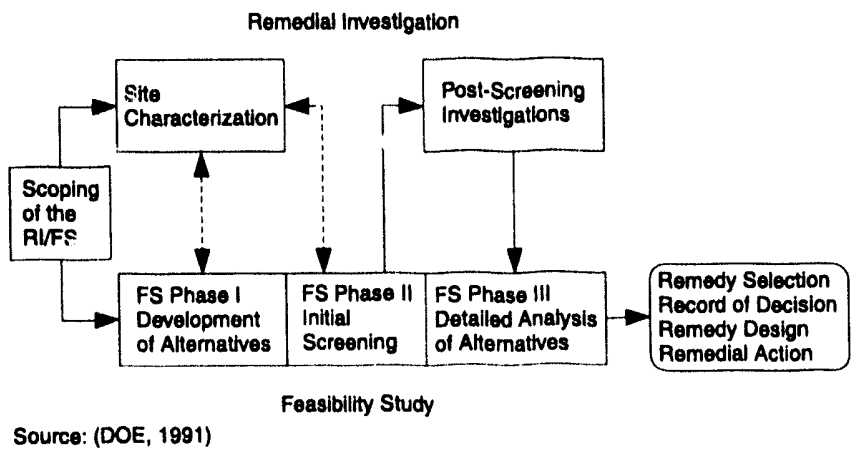

Figure 3. Overview of the CERCLA process

Site characterization in the RI includes the field investigations and laboratory analysis needed to generate the information for evaluating remedial alternatives. A baseline risk assessment must be conducted to identify existing and potential risks to human health and the environment posed by the site. The assessment of risks to the environment, including natural resources, requires the use of ecological risk assessment (ERA). Although the RI/FS process does not call for ERA until the RI phase, we believe that ERA-related activities should also be initiated during scoping so that the data needs for ERA can be incorporated into the RI work plans. During scoping, a "preliminary" ERA that uses existing data and an ecological reconnaissance to determine the nature of the environmental hazard posed by the released hazardous substances should be prepared. This step serves as a screen of potential contaminants, receptors, and routes of exposure to determine which of these are worthy of further investigation. The principal product of the preliminary ERA is a conceptual model of the hazard posed by the site that identifies significant sources, modes of release, pathways of 
transport, contaminated media, routes of uptake, primary receptors, secondary receptors (those exposed through food webs), and secondary effects such as loss of habitat or prey. (Note the similarities here to the Injury Determination step of the NRDA process.) Contaminants that appear to have the potential to cause ecological effects are termed contaminants of concern. Receptors that appear to be susceptible to contaminant exposures and have societal value or ecological importance are termed the assessment endpoints.

The preliminary ERA and its resulting conceptual model are then incorporated in the RI Work Plan and used to develop a list of data needs for the sampling and analysis plan. RI sampling and analysis inevitably include characterization of contaminant concentrations in environmental media, and should also include methods to measure ecological exposures (e.g., body burdens) and effects (e.g., toxicity tests), as well as surveys of abundance and species diversity. The results of the sampling and analysis are used to formulate the required baseline ERA, which addresses the risks associated with current and future conditions of the site assuming that no remedial action is taken and the site is not maintained. The risks associated with the "no-action" alternative determine whether remedial action is needed.

During the baseline ERA the conceptual model resulting from the preliminary ERA is refined on the basis of the information produced in sampling and analysis, and includes, for each contaminant or class of contaminants and each ecological assessment endpoint, assessments of exposure and the effects of varying levels of exposure. These exposure and effects assessments are then combined in a "risk characterization" to estimate the current and future baseline ecological risks. The risk characterization uses a weight-of-evidence approach to determine the best estimate of risk to each endpoint based on evidence from contaminant exposure levels, toxicity tests, and survers of the state of the receiving populations and communities. Tr, hase- 
line ERA appears in the RI report along with the baseline human health risk assessment and the results of the sampling and analysis. Readers needing more information on ERA should consult reference 15 through 20.

Phases I and II of the FS also begin soon after scoping, when likely response actions are first identified. Once remedial action objectives are established, potential treatment and containment technologies that satisfy these objectives are identified. Technologies are then screened for effectiveness, cost, and implementability, and assembled into alternatives. In the absence of sufficient site and/or treatment data, treatability tests may be needed to evaluate a particular technology on specific site wastes. These tests are generally bench-scale projects to assess the feasibility of a technology. Early implementation of pilotscale studies is recommended if there is a need for performance data and more complete cost estimates.

In Dhase III of an FS, remedial alternatives that survive the initial screening are evaluated in detail with respect to nine criteria established by EPA: protectiveness with regard to human health and the environment; compliance with ARARs; reduction of toxicity, mobility and volume of the contaminants; short-term effectiveness; long-term effectiveness; implementability; cost; state acceptance; and community acceptance. Alternatives are analy'zed individually against each criterion and then compared to each other to identify key tradeoffs that must be considered by decision makers. In this part of the process, risks to the environment of both construction and implementation of each alternative remedial action are also assessed. FS risk assessments are, however, much more uncertain than baseline ERAs because they depend on engineering estimates of the results of the remedial action and projections of exposure and effects from those estimates rather than on measured sources, exposures, and effects. 
The results of the RI/FS are synthesized for the remedy selection stage, which is chiefly a risk management decision that balances the acceptable range of values for protectiveness with costs and other important considerations that bear on the acceptability of the action. The preferred alternative is presented in a Proposed Plan, which must be made available for public comment. Once the public has had an opportunity to comment on the Proposed Plan, the Lead Agency selects a remedy. Detailed, enforceable performance criteria are then provided in a Record of Decision, which is signed by the lead agency and the EPA Regional Administrator. The project may then proceed to the design phase, after which the remedial action is actually implemented according to design specifications.

\section{Ecological Risk Assessment and NRDA Linkages}

Following the completion of the preliminary and baseline ERAs, the source of a hazardous substance exposure will have been identified and characterized, the pathways of exposure determined, and the ecological receptors identified. The data collected for these steps in the RI/FS would provide much of the information also needed for an NRDA should a decision to prepare an NRDA be made. DOE project managers should understand that whether or not to prepare an NRDA is a complex question that will probably not be a matter for DOE alone to decide, but will almost certainly require negotiation with cotrustees. Whether a decision to prepare an NRDA is made or not, the information derived from properly conducting the ecological risk assessment portion of the RI/FS can and should be used to address NRDA concerns to improve remedial action decisionmaking, as we explain below.

To most accurately estimate natural resource damages, an NRDA should really be conducted after completion of remedial action, because it is only at this point that residual injuries, i.e., those not addressed by the remedial action, can be accurately 
measured. In other words, the approach most likely to produce accurate results would be to base the NRDA on actual changes in contaminant exposure and effects during and immediately following remediation. It would, however, be unwise for RI/FS project managers to ignore NRDA concerns until then. Natural resource damage considerations really should play a role in the selection of remedial actions in the RI/FS process for maximum public benefit because some remedial action alternatives are likely to result in lower natural resource damages than others.

Ideally, remedial actions should be selected to provide the desired level of environmental quality for the lowest total cost, which we define as the cost of implementing the remedial action plus the natural resource damages associated with that action. Table 1 illustrates this idea. Restoration alternative $\mathrm{A}$ has the lowest implementation cost, but results in the highest natural resource damages. Conversely, alternative $\mathrm{D}$ has the highest implementation cost and the lowest natural resource damages. Alternative A might be the preferred alternative if natural resource damages are ignored, but it is alternative $B$ that results in the lowest total cost, while alternatives $\mathrm{A}$ and $\mathrm{C}$ result in the same total cost despite the much higher implementation cost of alternative $\mathrm{C}$.

Estimating natural resource damages before the implementation of remedial actions requires predicting how remediation will change contaminant levels and physical conditions, what natural resource service reductions would be associated with any residual injuries, and the value of these service reductions. Although there are uncertainties involved with such predictions, even highly uncertain estimates of damages can be useful if they allow the decisionmaker to avoid remedial actions that result in substantial residual injuries, thus minimizing future liability.

We wish to make clear that we are not recommending that the entire NRDA process be performed to provide estimates of 
damages for consideration in remedy selection. Knowledgeable economists, working with the environmental scientists responsible for ERA in the RI/FS process, can produce usable estimates for a relatively modest amount of additional effort.

Table 1. Hypothetical costs and associated damages for four possible remedial actions

\begin{tabular}{|c|c|c|c|}
\hline \multirow{2}{*}{$\begin{array}{c}\text { Possible } \\
\text { remedial } \\
\text { actions }\end{array}$} & $\begin{array}{c}\text { Implementation } \\
\text { costs } \\
(1)\end{array}$ & $\begin{array}{c}\text { Natural } \\
\text { resource damages } \\
(2)\end{array}$ & $\begin{array}{c}\text { Total cost } \\
(1)+(2)\end{array}$ \\
\hline A & 100 & 60 & 160 \\
\hline B & 120 & 30 & 150 \\
\hline C & 150 & 10 & 160 \\
\hline D & 195 & 5 & 200 \\
\hline
\end{tabular}

The integration of natural resource damages considerations in to the selection of remedial actions is not, however, likely to be without problems. First, the RI/FS process is often focused on individual OUs, while natural resource damages are more amenable to measurement at aggregated levels with ecological significance, such as watersheds. In many cases it would not be meaningful to try to determine the natural resource damages associated with individual OUs, and to the extent that remedial action decisions are made sequentially at this level, it may be difficult to make the kinds of comparisons illustrated in Table 1.

The second problem that may arise in trying to bring natural resource damages into the selection of a remedial action is that 
EPA, which has final decision authority on remedial actions, is not a natural resource trustee. EPA's remedy selection criteria do not include the natural resource damage implications of remedial actions, and EPA may not wish to add this element to its decisionmaking procedures.

Finally, although the concepts and tools of ERA and NRDA are similar, they are not identical. If the RI/FS is to serve NRDA needs, the missing NRDA requirements must be identified and added in planning the RI/FS. In particular, natural resource services, which are the focus of trustee interests, need to be included with the more common concerns as ecological assessment endpoints.

\section{Conclusions on Integrating the RI/FS and NRDA Processes}

Integrating the RI/FS and NRDA processes has several important advantages. First, integration should lead to the restoration of natural resource services sooner than a sequential approach, whereby natural resource damages are addressed only after the RI/FS process is completed. Integration should also lower the total cost of a hazardous substance release to the public for several reasons. Conducting an RI/FS is a costly exercise involving the expenditure of millions of dollars for the collection of data that are similar to the data needs of NRDA. By slightly expanding the RI/FS data collection, the information needed for the early phases of an NRDA could be acquired at modest additional cost. This would be much more efficient than spending millions of dollars on collecting data for an RI/FS and then spending millions more later if it becomes necessary to perform an NRDA and an independent data collection effort is required. Additionally, integrating the two processes will help ensure the selection of remedial actions that reduce the potential for natural resource damages. In some cases, higher remedy implementation costs may be more than offset by the concomi- 
tant decrease in natural resource damages. Finally, an integrated, proactive approach on natural resource damages may help avoid litigation, which is very costly and time-consuming.

While integrating the RI/FS and NRDA processes has many potential advantages, it also has potential disadvantages. First, as noted above, it is difficult to precisely estimate natural resource damages before the remedial actions are completed. Waiting until the completion of remedial actions would reduce uncertainty. Furthermore, since EPA is not a natural resource trustee, it may be reluctant to allow natural resource damages considerations to influence the selection of remedial actions. And since the steps in the NRDA process are not part of the RI/FS process, it may be difficult for DOE facilities to get funding for NRDA activities when budgets are based solely on $\mathrm{RI} / \mathrm{FS}$ activities. A proactive NRDA approach may also increase the likelihood that other trustees will bring an NRDA claim if lines of communication between DOE and other trustees break down. This kind of result should, however, be avoidable by bringing co-trustees into the decisionmaking process early and working to build consensus from the start.

Finally, the NRDA process is still evolving, with finalized revisions to the DOI regulations and new OPA regulations still to come. Important changes in the NRDA process are, therefore, possible in the next few years, which produces uncertainty about the usefulness of near-term NRDA activities. Overall, however, the potential advantages of integrating the RI/FS and NRDA processes substantially outweigh the potential disadvantages.

\section{References}

1. Ward, Kevin M. and John W. Duffield. 1992. Natural Resource Damages: Law and Economics. New York: John Wiley \& Sons.

2. 40 CFR 300 
3. 43 CFR 11

4. 40 CFR 300.600

5. U.S. Department of Energy. 1991. Natural Resource Trusteeship and Ecological Evaluation for Environmental Restoration at Department of Energy Facilities. DOE/EH-0192. RCRA/CERCLA Division, Office of Environmental Guidance, Washington, DC.

6. Marten, Bradley M., and Cestjon L. McFarland. 1991. "Litigating CERCLA Natural Resource Damage Claims." Environment Reporter July 19:670-677.

7. 43 CFR 11.10

8. 880 F. 2 d. 432

9. 56 Fed. Reg. 19752 (1991); and 58 FR 39328 (1993)

10. Desvousges, William H., F. Reed Johnson, Richard W. Dunford, Kevin J. Boyle, Sara P. Hudson, and K. Nicole Wilson. 1992. Measuring Nonuse Damages Using Contingent Vaiuation: An Experimental Evaluation of Accuracy. Monograph 92-1 prepared for Exxon Company, U.S.A. Research Triangle Park, NC: Research Triangle Institute.

11. 58 Fed. Reg. 4604 (1993)

12. 58 Fed. Reg. 4610 (1993)

13. 58 Fed. Reg. 4611 - 4614 (1993)

14. CERCLA 121

15. Risk Assessment Forum. 1992. Framework for Ecological Risk Assessment, EPA/630/R-92/001. U.S. Environmental Protection Agency. Washington, DC. 
16. U.S. Environmental Protection Agency. 1989. Risk Assessment Guidance for Superfund: Volume II: Environmental Evaluation Manual. EPA/540/1-89/001. Washington, DC.

17. Warren-Hicks, W., B. R. Parkhurst, and S. S. Baker, Jr. 1989. Ecological Assessment of Hazardous Waste Sites: A Field and Laboratory Reference. EPA/600/3-89/013. U.S. Environmental Protection Agency. Washington, DC.

18. Suter, G. W., II. 1993. Ecological Risk Assessment. Lewis Publishers, Chelsea, MI.

19. Maughan, J. T. 1993. Ecological Assessment of Hazardous Waste Sites. Van Nostrand Reinhold, New York.

20. Suter, G. W., II and J. M. Loar. 1992. Weighing the ecological risks of hazardous waste sites: the Oak Ridge case. Environ. Sci. Technol. 26:432-438. 
11
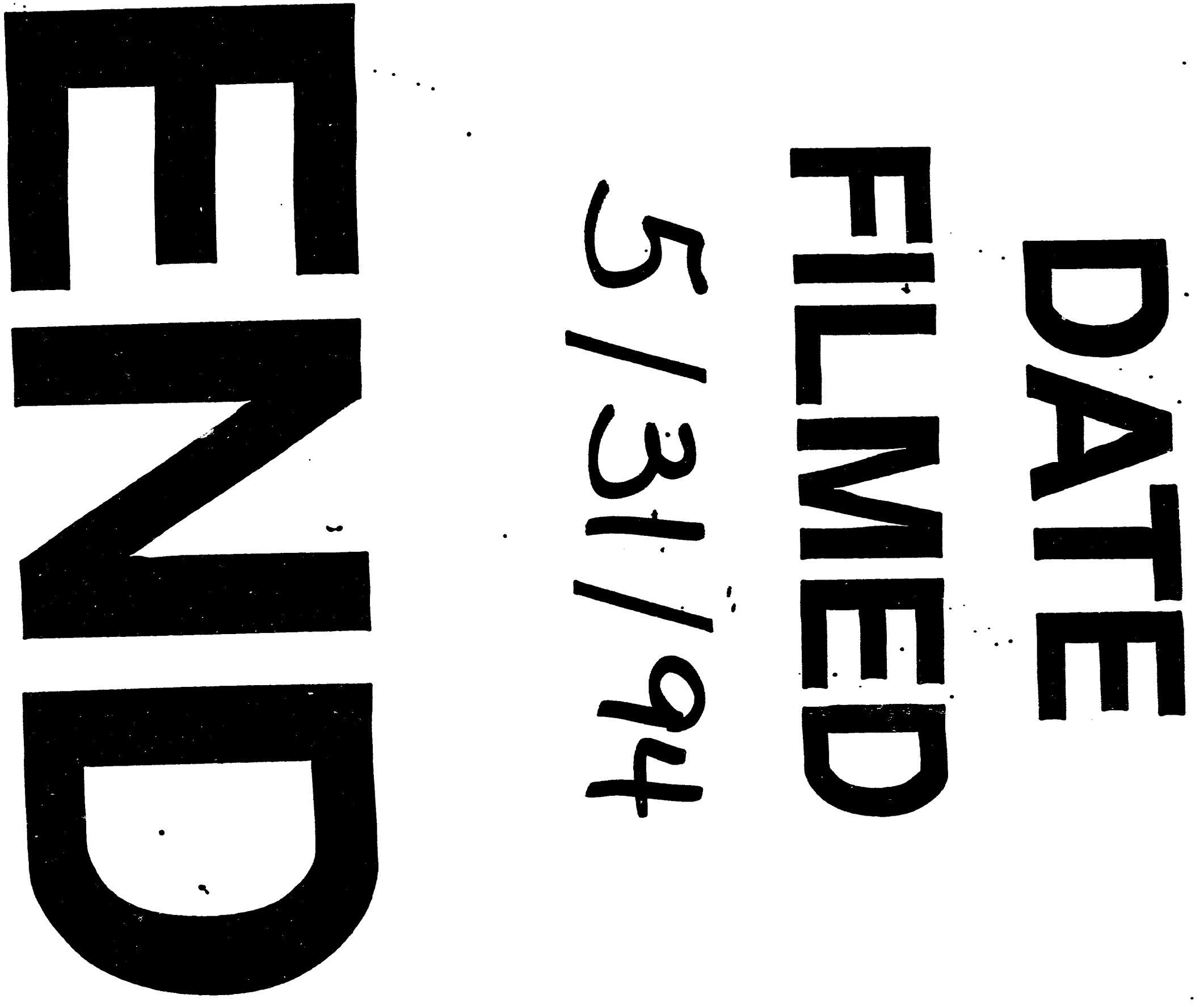
